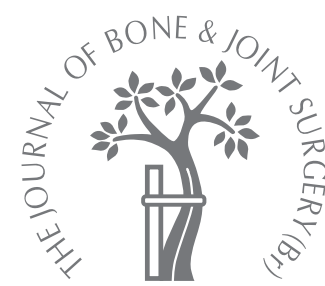

R. J. A. Goris, M. Leixnering, W. Huber, M. Figl, M. Jaindl, H. Redl

From the University Medical Centre, Nijmegen, The Netherlands

\title{
Delayed recovery and late development of complex regional pain syndrome in patients with an isolated fracture of the distal radius
}

\author{
PREDICTION OF A REGIONAL INFLAMMATORY RESPONSE BY \\ EARLY SIGNS
}

We studied prospectively the regional inflammatory response to a unilateral distal radial fracture in $\mathbf{1 1 4}$ patients at eight to nine weeks after injury and again at one year. Our aim was to identify patients at risk for a delayed recovery and particularly those likely to develop complex regional pain syndrome. In order to quantify clinically the inflammatory response, a regional inflammatory score was developed. In addition, blood samples were collected from the antecubital veins of both arms for comparative biochemical and bloodgas analysis.

The severity of the inflammatory response was related to the type of treatment (KruskalWallis test, $p=0.002$ ). A highly significantly-positive correlation was found between the regional inflammatory score and the length of time to full recovery $\left(r^{2}=0.92, p=0.01\right.$, linear regession). A regional inflammatory score of 5 points with a sensitivity of $100 \%$ but a specificity of only $16 \%$ also identified patients at risk of complex regional pain syndrome. None of the biochemical parameters studied correlated with regional inflammatory score or predicted the development of complex regional pain syndrome.

Our study suggests that patients with a distal radial fracture and a regional inflammatory score of 5 points or more at eight to nine weeks after injury should be considered for specific anti-inflammatory treatment.

R. J. A. Goris, MD, PhD, Emeritus Professor of Surgery Voshollei 2a bus 4f, 2930 Brasschaat, Belgium.

M. Leixnering, MD, Trauma Surgeon

M. Figl, MD, Trauma Surgeon Lorenz Böhler Hospital H. Redl, PhD, Professor Ludwig Boltzmann Institute for Experimental and Clinical Traumatology

Donaueschingenstrasse 13 A-1200 Vienna, Austria.

W. Huber, MD, Trauma Surgeon

UKH Linz, Garnisonstrasse 7, A-4017 Linz, Austria.

M. Jaindl, MD, Trauma Surgeon

Department of Traumatology University Hospital Währinge Gürtel 18-20, A-1090 Vienna, Austria.

Correspondence should be sent to Professor R. J. A. Goris; e-mail: rja.goris@skynet.be

C)2007 British Editorial Society of Bone and Joint Surgery doi:10.1302/0301-620X.89B8 $18620 \$ 2.00$

$J$ Bone Joint Surg $[\mathrm{Br}]$ 2007;89-B:1069-76. Received 6 September 2006 Accepted after revision 26 March 2007
The most commonly occurring fracture involves the distal radius. A poor correlation has been reported between the clinical outcome, patient satisfaction, the type of fracture and the radiological result. ${ }^{1-3}$ This suggests that factors other than these may affect the outcome.

Complex regional pain syndrome (CRPS), formerly referred to as reflex sympathetic dystrophy4 or Sudeck's atrophy, ${ }^{5}$ is often associated with a poor result after a fracture of the distal radius. ${ }^{6,7}$ After ten years, $62 \%$ of patients with an unsatisfactory outcome had objective features of CRPS compared with only $6 \%$ of those with satisfactory results. ${ }^{7}$ After a fracture of the distal radius, the reported incidence of CRPS varies between $8 \%$ and $35 \%$, depending on the clinical criteria applied $^{1,2,4,5,8,9}$ implying that there is a graduated response to this fracture from a normal recovery to that in which CRPS develops. Since local signs and symptoms of severe inflammation seem to precede the subsequent presentation of CRPS, we have prospectively studied these in a large series of patients who had a fracture of the distal radius in an attempt to determine predictors of a delayed recovery and the development of CRPS.
The definition of CRPS is still a matter of debate and continuous reassessment. ${ }^{10-14}$ Classically, the presence of severe pain is required to support the diagnosis, but $10 \%$ of patients with all the other signs and symptoms may not have significant pain. ${ }^{13,14}$ At present there is no sensitive and/or specific biochemical or imaging diagnostic tool which is available to identify CRPS. Technetium scanning ${ }^{15}$ and/or plain radiography ${ }^{16}$ is widely used, but is neither sensitive nor specific for establishment of the diagnosis. Field et $\mathrm{al}^{2}$ were able to differentiate between patients with CRPS, borderline and normal cases nine weeks after a Colles' fracture, based on the clinical criteria of finger tenderness, swelling, reduced range of finger movement, vasomotor instability and strength of grip.

Previous work has shown that in the presence of CRPS the venous oxygen saturation in the cubital vein was a mean of $18 \%$ higher than that in the unaffected arm. ${ }^{17-20}$ Huygen et $\mathrm{al}^{21}$ found increased levels of tumour necrosis factor $\alpha(\mathrm{TNF} \alpha)$ and Interleukin-6 (IL-6) in blister fluid on the affected side, while Blair et $\mathrm{al}^{22}$ noted elevated systemic levels of bradykinin. Koban et $\mathrm{al}^{23}$ using microdialysis, 
observed locally elevated levels of lactate and lower levels of cutaneous oxygen saturation. We have therefore attempted to ascertain what other factors correlating with the early inflammatory response may possibly predict the late development of CRPS. We chose to study the severity of the regional inflammatory response in the hand and fingers eight to nine weeks after a fracture of the distal radius and to determine whether this correlated with biochemical parameters in the venous efflux from the affected compared with the unaffected arm, and with the length of time to recover function and outcome after one year.

\section{Patients and Methods}

Permission for the study was granted by the Ethical Committee of the participating hospitals. Informed consent was obtained from all patients before enrolment into the study.

We recruited 114 patients (95 women, 19 men) with a mean age of 62 years ( 22 to 82 ) with an isolated unilateral fracture of the distal radius who were attending the fracture clinics of three Austrian hospitals over a period of six months (January to June 2003). They were enrolled in the study eight to nine weeks after the injury, at which stage the forearm cast, Kirschner-(K-)wires or external fixators had been removed for at least two weeks. Patients were excluded from the study if they had a residual deformity or a limited function and/or any recent injury in either arm before the fracture. The surgeons, who were not the authors, managing the patients referred them for physiotherapy and prescribed analgesia according to the respective hospital protocols (Lorenz Böhler Hospital, Vienna; University Hospital, Vienna; UKH Linz).

Comorbidities included diabetes in three patients, hypertension in six, and mild thyroid dysfunction in 26 . No patient had rheumatoid arthritis but 20 were cigarette smokers.

From radiographs the fractures were classified according to the AO system into type A, B or C. ${ }^{24}$ The type of treatment was recorded from the medical records into one of four groups: plaster of Paris, external fixation with or without percutaneous K-wires, internal fixation with a volar fixed angle palmar T-plate, or percutaneous K-wire fixation and plaster cast.

The fractures occurred on the right in 61 patients and the left in 53. The mean number of fracture manipulations was one ( 0 to 5$)$. When a plaster cast and/or an external fixator had been used, the mean duration of immobilisation of the fracture was five weeks (4 to 6). The external fixator was removed after three to four weeks and a plaster cast applied for the remaining period.

All the patients were seen by two of four trauma surgeons (RJAG, ML, WH, MJ) who were not involved in providing treatment. They were questioned as to whether they had experienced early signs of inflammation in the fractured arm. Subsequently, clinical measurements were performed in a fixed order. The methods used for measuring the inflammatory response had been previously described in prospective, randomised studies on CRPS $^{25,26}$ and were adapted slightly. After a period of acclimatisation for at least 15 minutes in a room with an ambient temperature set between $24^{\circ} \mathrm{C}$ and $25^{\circ} \mathrm{C}$, the patients were assessed for the presence of spontaneous pain using a visual analogue scale (VAS). They were asked to draw a line across a pre-printed horizontal line $10 \mathrm{~cm}$ in length, indicating the severity of pain at that moment, with $10 \mathrm{~cm}$ designating the most severe pain. A VAS of between $1 \mathrm{~cm}$ and $2 \mathrm{~cm}$ scored a severity of ' 0 ', of between $3 \mathrm{~cm}$ and $4 \mathrm{~cm}$ severity of ' 1 ', and of greater than $4 \mathrm{~cm}$ of ' 2 '.

Skin temperature was assessed by two instruments, an infrared ear thermometer (Genius; Sherwood Medical, Crawley, United Kingdom), as used in a previous study ${ }^{25,26}$ and by a ThermaCAM E2 infra-red camera (FLIR Systems $A B$, Danderyd, Sweden) mounted on a fixed support which allowed a single image of the dorsum of both hands to be acquired from a fixed distance. From these images, an area of $4 \mathrm{~cm}^{2}$ was identified in the middle of the dorsum of both hands, starting $1 \mathrm{~cm}$ proximal to the third metacarpophalangeal joint. The mean temperature of each hand was subsequently computed from this area. According to the findings of a previous study, ${ }^{26}$ a difference in temperature between the hands of between $0^{\circ} \mathrm{C}$ and $0.4^{\circ} \mathrm{C}$ scored ' 0 ', of between $0.5^{\circ} \mathrm{C}$ and $1^{\circ} \mathrm{C}$ ' 1 ', and of greater than $1^{\circ} \mathrm{C}$ ' 2 '. Since the results using the thermocamera did not differ from those using the ear thermometer, the data from the latter method were used for analysis.

Oedema was assessed by a custom-made device for measuring the circumference of the finger, consisting of a circular hole with incremental enlargement of the diameter by $0.8 \mathrm{~mm}$. This was applied to the middle section of the middle phalanx of the middle finger of both hands. A pilot study of 100 healthy normal volunteers aged between 18 and 82 years, had established that this method identified an increase of $0.8 \mathrm{~mm}$ in diameter in the dominant hand in 96 volunteers, with no difference in three ambidextrous volunteers and in one person who played the guitar. The severity of the oedema was graded 0 if the normal pattern was found, 1 if the difference equalled or exceeded $0.8 \mathrm{~mm}$ but was less than $1.6 \mathrm{~mm}$, and 2 if the difference equalled or exceeded $1.6 \mathrm{~mm}$ and/or when the dorsum of the hand was evidently swollen as documented by measurement of the circumference of the hand across the the index to the little finger metacarpals at the mid-level of these metacarpals.

The active range of movement was measured by a standard full-circle finger goniometer (Sulzer-Medica, Winterthür, Switzerland), measuring active extension and maximal active flexion of the proximal interphalangeal joints and metacarpophalangeal joints of the index, middle, ring and little fingers of both hands.

The reduction in active movement of each of these eight joints was calculated by subtracting recorded movement in the affected joint from the degree of movement found in the corresponding joint of the uninjured hand. The total loss of active movement was obtained by summating the results of 
Table I. Regional inflammation score (range 0 to 10 points)

\begin{tabular}{|c|c|c|c|}
\hline & \multicolumn{3}{|l|}{ Points } \\
\hline & 1 to 2 & 1 & 2 \\
\hline Visual analogue score for pain & 1 to 2 & 3 to 4 & $>4$ \\
\hline Difference in skin temperature of the hand $\left({ }^{\circ} \mathrm{C}\right)$ & 0 to 0.4 & 0.5 to 1 & $>1$ \\
\hline Oedema difference $(\mathrm{mm})$ & $<0.8$ & 0.8 to 1.5 & $\geq 1.6$ \\
\hline $\begin{array}{l}\text { Active range of movement } \\
\text { difference }\left({ }^{\circ}\right)\end{array}$ & 0 to 40 & 41 to 100 & $>100$ \\
\hline Skin colour difference & No & Slight & Obvious \\
\hline
\end{tabular}

the eight joints. We graded a loss of total active movement of $0^{\circ}$ to $40^{\circ}$ as 0 , a loss of $41^{\circ}$ to $100^{\circ}$ as 1 , and of more than $100^{\circ}$ as 2 .

Skin colour was assessed subjectively by two investigators (RJAG and ML, RJAG and HW, RJAG and MJ) as: no change, ' 0 ', some difference, ' 1 ', or obvious difference, ' 2 '.

Grip strength was measured by a baseline hydraulic hand dynamometer (Fabrication Enterprises Inc., Irvington, New York). The mean value of three successive readings after maximum effort for each hand was calculated. The results were then expressed as the percentage difference between the affected and normal hand, after applying a correction of $10 \%$ in recognition of the increased strength of the dominant hand.

From the examination for the presence of inflammatory signs, a regional inflammation score was calculated (Table I), by summing the subscores of five items, to produce a result ranging between 0 and 10 points.

Additionally, the patients were examined for the features of CRPS according to the modified International Association for the Study of Pain ${ }^{11}$ (ISAP) and the Nijmegen criteria. ${ }^{13}$ New radiographs were obtained and evaluated for evidence of demineralisation by consensus of two investigators (RJAG and ML) and scored according to Bickerstaff, Charlesworth and Kanis. ${ }^{27}$

Without using a tourniquet, blood samples $(2 \mathrm{ml})$ were obtained from the medial cubital vein for analysis of blood gases. Additional samples were aspirated in precooled polypropylene syringes, containing $0.2 \mathrm{ml}$ of cold inhibitor cocktail, mixed thoroughly and kept on ice until centrifugation for measurement of bradykinin. Finally a Vacuette system (Grauner Bio Gmbh, Kremsmuenster, Austria) was connected to the cannula and blood samples obtained within three vacuum tubes (one for serum (clotted blood supernatant), one ethylenediaminetetra-acetic acid (EDTA) tube (for decalcified plasma), and one heparinised (for plasma)).

The samples of blood gases, glucose and lactate were measured within ten minutes in an ABL System 600-Series (Radiometer, Copenhagen, Denmark). The others were assessed separately. After centrifugation at $4^{\circ} \mathrm{C}$ and at
$3500 \mathrm{rpm}$ for 15 minutes, $500 \mu \mathrm{l}$ of serum were snapfrozen in liquid nitrogen and stored at $-70^{\circ} \mathrm{C}$ for electron paramagnetic resonance (EPR). ${ }^{8}$ A further $500 \mu \mathrm{l}$ were stored at $-20^{\circ} \mathrm{C}$ for the assessment of neopterin, IL-1, 6 and 10 and TNF $\alpha$. From the EDTA tube $500 \mu \mathrm{l}$ were stored at $-20^{\circ} \mathrm{C}$ for the assessment of elastase and $500 \mu \mathrm{l}$ of plasma were snap-frozen in liquid nitrogen and stored at $70^{\circ} \mathrm{C}$ for EPR. The remaining plasma was stored at $-20^{\circ} \mathrm{C}$. From blood samples collected in the heparinised tubes, $500 \mu \mathrm{l}$ were snap-frozen in liquid nitrogen and stored at $70^{\circ} \mathrm{C}$ for EPR. The bradykinin and EPR analyses were performed in specialised institutions.

After one year, all patients were invited for re-examination by the same team and 89 reattended. Of the remaining 25 , three had died, three could not be traced or refused further participation, and complete medical records were available for the remaining 19 . These records were examined for reports of residual symptoms or for the presence of CRPS which did not appear to have occurred. This was subsequently confirmed by telephone interview. Therefore final follow-up data were available for 108 patients.

In the 89 patients who were examined, residual symptoms were recorded, and the clinical measurements made originally were repeated. The investigators (RJAG, ML, $\mathrm{WH}, \mathrm{MJ}$ ) were blinded to the results of the regional inflammation score calculated at eight to nine weeks after injury. This score was again calculated from the new data and assessment made for the presence of CRPS according to the modified IASP ${ }^{11}$ and Nijmegen ${ }^{13}$ criteria. Further radiographs were taken and scored for evidence of demineralisation of bone. The patient was asked how many months it had taken to achieve recovery to the condition before the fracture occurred and their response was crossreferenced with their medical records. The presence of CRPS was accepted if the patient's findings conformed to either or both of the IASP ${ }^{11}$ or Nijmegen ${ }^{13}$ criteria. Since some patients with severe symptoms also had a recent nerve injury with the affected area, no distinction was made between CRPS I and II.

Statistical analysis. This was performed using the MannWhitney $\mathrm{U}$ test for paired data and the Kruskal-Wallis test 
Table II. Relationship between skin temperature and regional inflammation score (RIS), grip strength, active range of movement and incidence of complex regional pain syndrome (CRPS) at eight to nine weeks after injury

\begin{tabular}{|c|c|c|c|c|c|}
\hline $\begin{array}{l}\text { Difference in skin temperature between } \\
\text { injured side and normal side }\end{array}$ & Number & $\begin{array}{l}\text { Mean RIS } \\
\text { (range) }\end{array}$ & $\begin{array}{l}\text { Mean grip strength } \\
\text { (range) }\end{array}$ & $\begin{array}{l}\text { Mean decrease in } \\
\text { active range of move- } \\
\text { ment }\left(^{\circ}\right) \text { (range) }\end{array}$ & CRPS \\
\hline Warmer $>0.4^{\circ} \mathrm{C}$ & 46 & 3.59 (1 to 9 ) & 43.0 (3 to 83 ) & $\begin{array}{l}-50(0 \text { to } 287) \\
x=16^{\dagger}\end{array}$ & 12 \\
\hline Cooler $>0.4^{\circ} \mathrm{C}$ & 12 & 2.08 (1 to 4$)$ & 68.1 (29 to 83 ) & 0 (0 to 0$)$ & 1 \\
\hline No temperature difference & 56 & 1.88 (0 to 6$)$ & $47.0(9$ to 100$)$ & $\begin{array}{l}-37(0 \text { to } 320) \\
x=14\end{array}$ & 3 \\
\hline
\end{tabular}

* mean grip strength as percentage of normal expected value

$\dagger \mathrm{x}=$ number of patients with reduced range of movement $>40^{\circ}$

Table III. Results related to initial skin temperature after one year

\begin{tabular}{|c|c|c|c|c|c|c|c|}
\hline $\begin{array}{l}\text { Difference in skin temperature between } \\
\text { injured side and normal side at } 8 \text { to } 9 \text { weeks }\end{array}$ & Number & $\begin{array}{l}\text { Mean RIS* } \\
\text { (range) }\end{array}$ & $\begin{array}{l}\text { Mean grip } \\
\text { strength }^{\dagger} \text { (range) }\end{array}$ & $\begin{array}{l}\text { Mean active range } \\
\text { of movement }\left(0^{\circ}\right)\end{array}$ & CRPS $^{\ddagger}$ & $\begin{array}{l}\text { Mean time to } \\
\text { recovery in } \\
\text { mths (range) }\end{array}$ & $\begin{array}{l}\text { Number } \\
\text { recovered } \\
\text { by } 2 \text { mths }\end{array}$ \\
\hline Warmer $>0.4^{\circ} \mathrm{C}$ & 40 & 0.83 (0 to 6$)$ & $83.7(27$ to 100$)$ & $x^{\S}=2$ & 2 & 4.9 (2 to 12$)$ & 29 \\
\hline Cooler $>0.4^{\circ} \mathrm{C}$ & 8 & 0.25 (0 to 2 ) & $96.3(70$ to 100$)$ & $x=0$ & 0 & 2.1 (2 to 3 ) & 1 \\
\hline No temperature difference & 41 & 0.71 (0 to 6$)$ & $84.3(10$ to 100$)$ & $x=2$ & 2 & 3.9 (2 to 12 ) & 19 \\
\hline
\end{tabular}

* RIS, regional inflammation score

† mean grip strength as percentage of normal expected value

₹ CRPS, complex regional pain syndrome

$\S x$, number of patients with reduced range of movement $>40^{\circ}$

for non-parametric data. Dunn's multiple comparison posttest was used for comparison between groups and the regression coefficient with $95 \%$ confidence interval (CI) for analysis of the regional inflammation score at eight to nine weeks versus time to full recovery. A p-value of $\leq 0.05$ was considered to be significant.

\section{Results}

At eight to nine weeks the skin temperature was the same in both hands in 56 patients $(49.1 \%)$, warmer by $0.5^{\circ} \mathrm{C}$ or more in the injured side in $46(40.3 \%)$ and cooler in the injured side by $0.5^{\circ} \mathrm{C}$ or more in $12(10.6 \%)$. After one year the difference in the skin temperature between the injured arm and the uninjured arm exceeded $0.4^{\circ} \mathrm{C}$ in four patients $(4.5 \%)$ and $-0.4^{\circ} \mathrm{C}$ in 21 patients $(23.6 \%)$. In those who were examined it was the same. The mean VAS at eight to nine weeks was 2.1 ( 1 to 9 ) and the mean VAS at one year was one (1 to 7$)$. After one year four patients (4.5\%) had a VAS greater than 2 points. One patient $(1.1 \%)$ had a score of 3 because of shoulder pain, and three $(3.4 \%)$ had scores of 6, 6 and 7 respectively resulting from CRPS. At eight to nine weeks, the active range of movement was decreased by more than $40^{\circ}$ in 27 patients $(23.7 \%)$. At one year it was normal in all but five patients $(5.6 \%)$ for whom the reduction in range was more than $40^{\circ}$ in four patients $(4.5 \%)$. Three $(3.4 \%)$ of these five patients had CRPS, one had dementia and one was an alcoholic with malunion of the radius.
The mean regional inflammation score at eight to nine weeks was 2.9 points (0 to 9). In 19 patients $(16.6 \%$ ) the score was five or higher. After one year it was 0.60 (0 to 6). In patients with a skin temperature exceeding $+0.4^{\circ} \mathrm{C}$ at eight to nine weeks in the affected hand the regional inflammation score was significantly higher than in the other patients (Kruskal-Wallis test, $\mathrm{p}<0.001$ ) and the strength of grip was significantly reduced compared with that when the skin temperature was cooler by at least $0.4^{\circ} \mathrm{C}$ (KruskalWallis test, $\mathrm{p}<0.05$ ) (Table II).

After one year, patients whose injured side had a reduced skin temperature at eight to nine weeks had a better mean strength of grip of $96 \%(70 \%$ to $100 \%)$ of the expected normal value (Kruskal-Wallis test, $\mathrm{p}<0.05$ ), a shorter mean time to recovery of 2.1 months (2 to 3 )(KruskalWallis test, $\mathrm{p}<0.01)$ and had usually recovered at two months after injury (Kruskal-Wallis test, $\mathrm{p}<0.0001$ ) compared with those with an elevated skin temperature at eight to nine weeks (Table III). However, patients who after one year had a difference in hand temperature of more than $0.4^{\circ} \mathrm{C}$ (cooler or warmer) had a significantly higher RIS than when there was no temperature difference (KruskalWallis test, $\mathrm{p}<0.001$ if cooler, $\mathrm{p}<0.01$ if warmer). If cooler the strength of grip, the time to recovery and the number of patients requiring more than two months for recovery were significantly higher than if there was no temperature difference (Dunn's multiple comparision post-test, $\mathrm{p}<0.05$ ) (Table IV). 
Table IV. Skin temperature at one year

\begin{tabular}{|c|c|c|c|c|c|c|c|}
\hline $\begin{array}{l}\text { Difference in skin temperature between } \\
\text { injured side and normal side }\end{array}$ & Number & $\begin{array}{l}\text { Mean RIS* } \\
\text { (range) }\end{array}$ & $\begin{array}{l}\text { Mean grip } \\
\text { strength }^{\dagger} \text { (range) }\end{array}$ & $\begin{array}{l}\text { Range of } \\
\text { movement }\left({ }^{\circ}\right)\end{array}$ & CRPS $^{\ddagger}$ & $\begin{array}{l}\text { Mean time to } \\
\text { recovery in } \\
\text { mths (range) }\end{array}$ & $\begin{array}{l}\text { Number not } \\
\text { recovered by } \\
2 \text { mths }\end{array}$ \\
\hline Warmer $>0.4^{\circ} \mathrm{C}$ & 4 & 2.25 (1 to 4 ) & $86.3(12$ to 100$)$ & $x^{\S}=2$ & 0 & 8.0 (3 to 12$)$ & 4 \\
\hline Cooler $>0.4^{\circ} \mathrm{C}$ & 21 & 2.05 (0 to 6$)$ & $72.2(10$ to 100$)$ & $x=2$ & 4 & 5.7 (2 to 12$)$ & 15 \\
\hline No temperature difference & 64 & $0.19(0$ to 2$)$ & $91.0(27$ to 100$)$ & $x=0$ & 0 & 3.5 (2 to 12$)$ & 30 \\
\hline
\end{tabular}

The relationship between the type of fracture and the regional inflammation score indicated that the initial score was significantly higher in type-C than in type-A fractures (Kruskal-Wallis test, $p<0.05$ ). Grip strength at first examination was highly significantly different between fracture categories (Kruskal-Wallis test, $\mathrm{p}=0.003$ ) with a significant reduction in patients with type-C compared with those with type-A fractures (Dunn's multiple comparison test, $p<0.001)$. No significant differences were found between the type of fracture, limitation in the active range of movement and the time to full recovery.

The relationship between the type of treatment and the regional inflammation score, strength of grip, active range of movement, CRPS at both time points and time to full recovery of function, indicated that there was a significant difference between treatment groups at eight to nine weeks for regional inflammation score (KruskalWallis test, $\mathrm{p}=0.002$ ), grip strength (Kruskal-Wallis test, $p=0.0002)$, limitation in active range of movement (Kruskal-Wallis test, $\mathrm{p}<0.0001$ ) and time to full recovery (Kruskal-Wallis test, $\mathrm{p}<0.004)$. Plate fixation $(\mathrm{n}=17)$ and external fixation $(n=6)$ were mainly used in type-C fractures. When these were compared, plate osteosynthesis was found to have a significantly lower regional inflammation score (Dunn's multiple comparison posttest, $\mathrm{p}<0.05$ ), reduction in grip strength (Dunn's multiple comparison test, $\mathrm{p}<0.05$ ), initial reduction in active range of movement (Dunn's multiple comparison test, $\mathrm{p}<$ 0.001 ) and time to full recovery (Dunn's multiple comparison test, $\mathrm{p}<0.05)$. No significant differences were found between the plate osteosynthesis and plaster-of-Paris groups and similarly after one year between treatment groups.

No significant relationship was found between preexisting pre-morbid conditions, smoking, subtypes of fracture, the anatomical end result, complications and the maximum regional inflammation score or the incidence of CRPS.

At eight to nine weeks after injury, 16 patients (14 women, 2 men) (14\%) had CRPS, ten (9\%) according to the modified IASP criteria and $13(11.4 \%)$ according to the Nijmegen criteria. Of these 16 patients, seven fitted both criteria, three only the IASP criteria, and six only the Nijmegen criteria.

After one year four $(4.5 \%)$ female patients had CRPS. Three according to the IASP criteria, including one with a regional inflammation score of 4 points but with sympathetic signs. Three were positive for the Nijmegen criteria including one negative for the IASP criteria with a VAS score of 1 . Their regional inflammation scores at eight to nine weeks were $3,5,5,7$ points, and after one year $4,5,6,6$ points, respectively. Three had a temperature increase in the affected limb and were already positive for CRPS shortly after injury. One of these three, with an initial regional inflammation score of 5 points, had a painful neuroma of the superficial radial nerve, which was not treated. Four months after the injury, she fractured the radius on the contralateral side which was also complicated by CRPS. At one year the regional inflammation score on the side of the first fracture had increased to 6 points. The fourth patient had an initial regional inflammation score of 3 , and had a rupture of the tendon of extensor pollicis longus and severe carpal tunnel disease. The latter was decompressed nine months after the original injury. The symptoms of CRPS only developed after this operation and she was positive for the IASP criteria after one year when her regional inflammation score was 4 points. At the first examination, none of the four patients who developed late CRPS had a temperature difference of more than $1^{\circ} \mathrm{C}$. Oedema of severity grade 1 was present in only two of these patients. Only three patients had an initial regional inflammation score above 4 points, while 18 patients $(20.2 \%)$ who did not develop late CRPS had a similarly high initial score. Only two of the four patients had an initial reduction in the active range of movement of more than $100^{\circ}$ compared with 18 (20.2\%) who did not develop late CRPS. Only one of these four late CRPS patients had abnormal sweating while this was found in 12 other patients $(13.5 \%)$. Abnormal hair growth at first examination was found in seven patients $(6.1 \%)$ (four of whom satisfied the criteria for CRPS), and was present in two earlier CRPS patients out of four who developed late CRPS.

At the first examination, nine patients $(7.9 \%)$ of $114 \mathrm{had}$ a nerve dysfunction, three $(2.6 \%)$ had carpal tunnel syndrome and six $(5.3 \%)$ had a neuroma of the superficial 
Table V. Hand skin temperature in relation to the initial regional inflammation score (RIS) and venous oxygen saturation

\begin{tabular}{lclc}
\hline Skin temperature & Number & Mean initial RIS (range) & SVO $_{2}{ }^{*}$ (\%) \\
\hline Warmer or equal & 82 & $2.76(0$ to 9$)$ & +10.21 \\
Cooler & 24 & $2.07(0$ to 6$)$ & +2.91 \\
\hline * $\mathrm{SVO}_{2}$, difference in oxygen saturation in blood sampled from the anticubital vein \\
between the fractured and uninjured side
\end{tabular}

radial nerve due to insertion of $\mathrm{K}$-wires or an external fixator pin. Of these nine patients, one conformed to the IASP criteria for CRPS at first examination. After one year, two conformed to the IASP criteria and one to the Nijmegen criteria. In one patient the external fixator loosened, with early positive Nijmegen criteria, but signs had subsided after one year. In one patient with K-wires inserted three extensor tendons ruptured and the patient was positive by IASP criteria for CRPS at the initial examination, but this resolved. Other complications included a spontaneous rupture of the tendon of extensor pollicis longus in four patients $(4.5 \%)$, one of whom had CRPS, one with a small area of skin necrosis from a plaster-of-Paris cast, and one with loosening of a volar plate which required re-fixation without further problems.

The mean grip strength of the fractured side at first examination was $13.2 \mathrm{~kg}$ ( 1 to $36,47.4 \%$ of normal) compared with a mean of $27.9 \mathrm{~kg}$ (5 to $52,87.2 \%$ of normal) for the uninjured side but was only $7.2 \mathrm{~kg}$ (4 to $13,25.0 \%$ of normal) in the four late CRPS patients (Mann Whitney U test, $\mathrm{p}=0.024$ ). After one year, it had increased to $25.4 \mathrm{~kg}$ versus $28.4 \mathrm{~kg}$ on the uninjured side. The grip strength at one year was $80 \%$ of normal or less in nine patients $(7.9 \%)$, including the four late CRPS patients.

A normal use of the affected limb at two months after injury was reported by 40 patients (45\%). Recovery to normal exceeded six months in 12 patients (13\%), in four $(4.5 \%)$ because of CRPS and other problems, in three $(3.3 \%)$ due to carpal tunnel syndrome, in three $(3.3 \%)$ to pain attributed to the triangular ligament, in one to shoulder pain, in one $(1.1 \%)$ to rupture of extensor pollicis longus and in one $(1.1 \%)$ to malunion in an alcoholic patient. There was a highly significant positive correlation between the initial regional inflammation score and the overall length of recovery (regression coefficient $r^{2}=0.92$, linear regression $p=0.01$ ) and for recovery within two months $\left(\mathrm{r}^{2}=0.89\right.$, linear regression $\mathrm{p}=0.016)$. The delay was in part caused by complications and the presence of CRPS, but disregarding the 15 patients with complications present at eight to nine weeks, the initial regional inflammation score in the other 74 also correlated with the length of recovery $\left(r^{2}=0.978\right.$, linear regression $\mathrm{p}=0.002$ ), and for recovery within two months $\left(r^{2}=0.8115\right.$, linear regression $\left.\mathrm{p}=0.014\right)$. In the four late CRPS patients recovery lasted six months in one, while the others were not fully recovered at 12 months.

In the fractured arm the mean venous oxygen saturation $\left(\mathrm{SVO}_{2}\right)$ was $75.9 \%(18.9 \%$ to $98.1 \%)$ compared with $67.2 \%(28.5 \%$ to $94.1 \%)$ in the healthy limb (Wilcoxon signed-rank test for paired values, $\mathrm{p}<0.0001)$. In patients with no temperature difference or warmer affected arm, the venous oxygen saturation was significantly higher than when the injured arm was cooler (Mann Whitney U test, $\mathrm{p}=0.016$ ) (Table V). The difference in $\mathrm{SVO}_{2}$ between the injured and normal side varied between $+42.8 \%$ and $-62 \%$ saturation in absolute values. The $\mathrm{SVO}_{2}$ difference in the injured arms of the four late CRPS patients was $-13.7 \%,+16 \%,+18.9 \%$ and $+23 \%$, respectively, within the range of the whole study population.

None of the measured biochemical and EPR parameters were different from normal control values or had a left-to-right difference, correlating with the initial regional inflammation score and/or later CRPS.

At eight to nine weeks after the injury, radiological images of both hands identified some of the feactures of bone demineralisation generally attributed to CRPS, in $46(40 \%)$ of the patients.

\section{Discussion}

Our study has shown a great variation in the regional inflammatory response in the hand and fingers to a fracture of the distal radius eight to nine weeks after injury. This seemed to be partly dependent on the type of fracture and the type of treatment. In particular, patients with a difference in skin temperature of more than $0.4^{\circ} \mathrm{C}$ at eight to nine weeks had a significantly higher regional inflammation score. Compared with the patients with a cooler hand they had less strength of grip and a longer time to recovery. This suggests that, for a better outcome, the inflammatory response should have subsided eight to nine weeks after injury. In addition, patients treated by internal fixation using a volar plate had a significantly better result than those treated by an external fixator.

The second aim of our study was to examine the relationship between the inflammatory response and biochemical parameters. However, we were unable to establish any relationship between the lactate and the level of inflammatory meditors in the venous efflux from the affected compared with the unaffected arm. Large variations in the venous 
oxygen saturation are present in the antecubital veins of normal subjects depending on skin temperature, ${ }^{28}$ ambient temperature $^{29}$ and body temperature. ${ }^{30}$ In a limb affected with CRPS, venous oxygen saturation levels are excessively high. ${ }^{17-20}$ Our findings showed that, although such elevated levels were found, even when the hand skin temperature was lower than that in the healthy hand, venous oxygen saturation did not correlate well with the regional inflammation score and/or with CRPS. This may be because the sampled blood was draining the skin and subcutaneous layers and was not specifically sampling efflux from the hand. We have confirmed that the inflammatory response correlated strongly with the length of recovery of function, with outcome after one year, and with the occurrence of CRPS.

Several clinical parameters have been suggested as being helpful in identifying CRPS, such as skin temperature, ${ }^{5,31-36}$ a decrease in active range of movement, ${ }^{6,35}$ oedema, ${ }^{6,35}$ pain, $2,35,37$ a decrease in grip strength ${ }^{6,37}$ and sympathetic signs. In our study none of these, taken individually, was sensitive and/or specific for the identification of CRPS at an early stage. Combining several of these parameters improved the likelihood of identifying CRPS. Field et $\mathrm{al}^{2}$ used tenderness and stiffness of the fingers, vasomotor instability and swelling as criteria for CRPS. Applying these criteria, CRPS was identified one week after injury in 24 of 100 patients with a Colles' fracture. ${ }^{6}$ Schurmann et al $^{35}$ found combined clinical signs had a sensitivity of $78 \%$ and a specificity of $94 \%$ for identifying CRPS 16 weeks after injury. ${ }^{5}$

In our study, three of four late CRPS patients already conformed to the IASP ${ }^{11}$ and Nijmegen ${ }^{13}$ criteria at first examination but in total, 16 patients $(14 \%)$ at the initial examination also satisfied these criteria for CRPS. An initial regional inflammation score of 5 points or higher identified late CRPS in three of the four patients. In the fourth the initial regional inflammation score was 3 , and the signs and symptoms appeared after nine months after decompression for carpal tunnel syndrome on the affected wrist. If this case was excluded, an initial regional inflammation score of 5 or higher detected later CRPS with $100 \%$ sensitivity but since a regional inflammation score of 5 or higher was found initially in a total of 19 patients $(16.6 \%)$, the specificity of this cut-off point was only $16 \%$.

Several studies have shown that the severity of the fracture does not seem to affect the tendency to develop CRPS. ${ }^{1,2}$ In our study, type- $C$ fractures had a significantly higher initial regional inflammation score than type-A fracture, but the incidence of late CRPS was too low to draw any conclusions. Other reports have found no relationship between the occurrence of CRPS and radial shortening, radial angulation, dorsal tilt or styloid of the ulna fracture. ${ }^{1,3,6}$ In the study of Gradl et al, ${ }^{5}$ radiography had a low sensitivity (33\%) but a high specificity $(91 \%)$ for identifying CRPS. In our study eight to nine weeks after injury, the pattern of bone demineralisation attributed to CRPS occurred in $40 \%$ of the patients.
Depending on the definitions used, the incidence of CRPS after a fracture of the distal radius varies between $8 \%$ and $35 \%,{ }^{1,2,4,5,8,9}$ but after ten years it is only $2 \% .^{6}$ In our study, at eight to nine weeks after injury, early CRPS was identified in $9 \%$ of patients according to the modified IASP criteria and in $12 \%$ on the basis of the Nijmegen criteria. After one year, this was reduced to $4.5 \%$.

After assessing various clinical, radiological and biochemical diagnostic parameters and two criteria for early identification of patients with CRPS after a distal radial fracture, none was found to be sensitive and/or specific. However, three of four patients with late CRPS had an initial regional inflammation score of 5 or more points, and this level of initial regional inflammation score was also present in $95 \%$ of the patients with a prolonged time to full recovery, with a mean of more than six months. Therefore special attention should be given to patients with a regional inflammation score of 5 points or more at approximately eight weeks after injury. It has been shown that prophylactic administration of vitamin $\mathrm{C}$ reduces the inflammatory response in Colles' fractures, ${ }^{4}$ while early treatment with specific anti-inflammatory drugs such as corticosteroids ${ }^{38}$ and radical scavengers ${ }^{39,40}$ have a proven therapeutic value in reducing these inflammatory signs. Therefore prophylaxis with vitamin $\mathrm{C}$ should be considered for all patients with a distal radial fracture, and based on our findings early treatment commenced with specific anti-inflammatory drugs if the regional inflammation score exceeds 4 points at eight weeks after injury. We accept that this requires further investigation.

\section{Supplementary Material}

$\because$ A further opinion by Miss M. M. McQueen is available with the electronic version of this article on our website at www.jbjs.org.uk

We thank Prof Dr V. Vessei (University Hospital, Vienna), Prof Dr H. Hertz (Lorenz Böhler Hospital, Vienna and Pivat Docent Dr A. Kropfl (UKH Linz) for permission to examine their patients. Mrs I. Jung performed the statistical analysis. Bradykinin was analysed in the laboratory for Clinical Chemistry and Clinical Biochemistry, University Hospital of Surgery Germany (Prof Dr E. Fink). Electron paramagnetic resonance analysis was performed in the Institute for Pharmacology and Toxicology, University of Veterinary Medicine (Prof Dr H. Nohl, Vienna, Austria). We thank the collaborators of the Ludwig Boltzman Institute for Experimental and Clinical Traumatology, Vienna, Austria, for volunteering in several pilot studies.

No benefits in any form have been received or will be received from a commercial party related directly or indirectly to the subject of this article.

\section{References}

1. Atkins RM, Duckworth T, Kanis JA. Features of algodystrophy after Colles' fracture. J Bone Joint Surg [Br] 1990;72-B:105-10.

2. Field J, Protheroe DL, Atkins RM. Algodystrophy after Colles fractures is associated with secondary tightness of casts. J Bone Joint Surg [Br] 1994;76-B:901-5.

3. Roumen RM, Hesp WL, Bruggink ED. Unstable Colles' fractures in elderly patients: a randomised trial of external fixation for redisplacement. J Bone Joint Surg [Br] 1991;73-B:307-11.

4. Zollinger PE, Tuinebreijer WE, Kreis RW, Breederveld RS. Effect of vitamin C on frequency of reflex sympathetic dystrophy in wrist fractures: a randomised trial. Lancet 1999;354:2025-8.

5. Gradl G, Steinborn M, Wizgall I, Mittlmeier T, Schurmann M. Acute CRPS I (morbus sudeck) following radial fractures: methods for early diagnosis. Zentralb/ Chir 2003;128:1020-6 (in German). 
6. Field J, Atkins RM. Algodystrophy is an ealry complication of Colle's fracture: what are the implications? J Hand Surg [Br] 1997;22:178-82.

7. Warwick D, Field J, Prothero D, Gibson A, Bannister GC. Function ten years after Colles' fracture. Clin Orthop 1993;295:270-4.

8. Atkins RM, Duckworth T, Kanis JA. Algodystrophy following Colles' fracture. $J$ Hand Surg [Br] 1989;14:161-4.

9. Van Raaj JJ, Boot C, Oostvogel HJ, van der Werlen C. External fixation of unstable wrist fractures. Ned Tijdschr Geneesd, 1990;138:1607-11 (in Dutch).

10. BruehI S, Harden RN, Galer BS, et al. Complex regional pain syndrome: are there distinct subtypes and sequential stages of the syndrome? Pain 2002;95:119-24.

11. BruehI S, Harden RN, Galer BS, et al. External validation of IASP diagnostic criteria for Complex Regional Pain Syndrome and proposed research diagnostic criteria. Pain 1999;81:147-54.

12. Galer BS, BruehI S, Harden RN. IASP diagnostic criteria for complex regional pain syndrome: a preliminary empirical validation study. Clin J Pain 1998;14:48-54.

13. Veldman PH, Reynen HM, Arntz IE, Goris RJ. Signs and symptoms of reflex sympathetic dystrophy: prospective study of 829 patients. Lancet 1993;342:1012-16.

14. Eisenberg E, Melamed E. Can complex regional pain syndrome be painless? Pain 2003;106:263-7

15. Werner R, Davidoff G, Jackson MO, et al. Factors influencing the sensitivity and specificity of the three-phase technetium bone scan in the diagnosis of reflex sympathetic dystrophy syndrome in the upper extremity. J Hand Surg 1989;14:520-3.

16. Tudorovic-Tirnavic M, Obradovic V, Han R, et al. Diagnostic approach to reflex sympathetic dystrophy after fracture: radiography or bone scintography. Eur J Nucl Med 1995;22:1187-93.

17. Bolliger A. Vascular reactions and their role in the occurrence of Sudeck's syndrome. Helv Chir Acta 1954;21:61-86.

18. Goris RJ. Conditions associated with impaired oxygen extraction. In: Gutierrex G Vincent JL, eds. Tissue oxygen utilization. Berlin: Springer-Verlag, 1991:350-69.

19. Matsumura H, Jimbo Y, Watanabe K. Haemodynamic changes in early phase reflex sympathetic dystrophy. Scand J Plast Reconstr Surg Hand Surg 1996;30:133-8.

20. Stolte BH, Stolte JB, Leyten JF. Pathophysiology of the shoulder-hand syndrome. Ned Tijdschr Geneeskd 1970;114:1208-9 (in Dutch).

21. Huygen JP, De Bruijn AG, De Bruin MT, et al. Evidence for local inflammation in complex regional pain syndrome type 1. Mediators Inflamm 2002;11:47-51.

22. Blair SJ, Chinthagada M, Hoppenstehdt D, Kijowski R, Fareed J. Role of neuropeptides in pathogenesis of reflex sympathetic dystrophy. Acta Orthop Belg 1998;64:448-51.

23. Koban M, Leis S, Schultz-Mosgau S, Birklein F. Tissue hypoxia in complex regional pain syndrome. Pain 2003;104:149-57.

24. Müller ME. Comprehensive classification of fractures. Bern: Muller ME Foundation, 1996.
25. Oerlemans HM, Oostendorp RA, de Boo Th, Perez RS, Goris RJ. Signs and symptoms in reflex sympathetic dystrophy: judgement of the physician versus measurement outcomes. Clin J Pain 1999;1:224-32.

26. Oerlemans HM, Oostendorp RA, Goris RJ, de Boo Th. Pain and reduced mobility in complex regional pain syndrome. I: outcome of a randomised controlled trial of adjuvant physiotherapy versus occupational therapy. Pain 1999;83:77-83.

27. Bickerstaff DR, Charlesworth D, Kanis JA. Changes in cortical and trabecular bone in algodystrophy. Br J Rheumatol 1993;32:46-51.

28. Schramm WM, Bartunek A, Gilly H. Effect of local limb temperature on pulse oximetry and the plethysmographic pulse wave. Int J Clin Monit Comput 1997:14:17-

29. Reed HL, Pepper S, Armstrong D, Von Tersch FJ, Lewis SB. Oxygen saturation of brachial venous blood correlates with fingertip temperatures between 11 and 39 degrees C. Aviat Space Environ Med 1989;60:1068-71.

30. Benzon HT, Toleikis JR, Meagher LL, et al. Changes in venous blood lactate, venous blood gases, and somatosensory evoked potentials after tourniquet application. Anesthesiology 1988;69:677-82.

31. Christensen $\mathbf{K}$, Henriksen $\mathbf{0}$. The reflex sympathetic dystrophy syndrome: an experimental study of sympathetic reflex control of subcutaneous blood flow in the hand. Scand J Rheumatol 1983;12:263-7.

32. Schurmann M, Zaspel J, Gradl G, Wipfel A, Christ F. Assessment of the peripheral circulation using computer-assisted venous congestion plethysmography in post traumatic complex regional pain syndrome type I. J Vasc Res 2001;38:453-61.

33. Wasner G, Schattschneider J, Baron R. Skin temperature side differences: a diagnostic tool for CRPS? Pain 2002;98:19-26.

34. Bej MD, Schwartzman RJ. Abnormalities of cutaneous blood flow regulation in patients with reflex sympathetic dystrophy as measured by laset Doppler fluxmetry. Arch Neurol 1991;48:912-15.

35. Schurmann M, GradI G, Zaspel J, et al. Peripheral sympathetic function as a predictor of complex regional pain syndrome type I (CRPS I) in patients with radial fracture. Auton Neurosci 2000;86:127-34

36. Birklein F, Kunzel W, Sieweke N. Despite clinical similarities there are significant differences between acute limb trauma and complex regional pain syndrome I (CRPS I). Pain 2001;93:165-71

37. Wakefield AE, McQueen MM. The role of physiotherapy and clinical predictors of outcome after fracture of the distal radius. J Bone Joint Surg [Br] 2000;82-B:972-6.

38. Christensen K, Jensen EM, Noer I. The reflex dystrophy syndrome response to treatment with systemic corticosteroids. Acta Chir Scand 1982;148:653-5.

39. Goris RJ, van Dongen LM, Winters HA. Are toxic oxygen radicals involved in the pathogenesis of reflex sympathetic dystrophy? Free Radic Res Commun 1987;3:13-18.

40. Zuurmond WW, Langendijk PN, Bezemer PD, et al. Treatment of acute reflex sympathetic dystrophy with DMSO $50 \%$ in a fatty cream. Acta Anaesthesiol Scand 1996:40:364-7. 